\title{
One third of patients with radiotherapy-induced nausea consider their antiemetic treatment insufficient
}

\author{
Anna Enblom • Beata Bergius Axelsson • \\ Gunnar Steineck • Mats Hammar • Sussanne Börjeson
}

Received: 7 November 2007 / Accepted: 13 March 2008 / Published online: 5 June 2008

(C) The Author(s) 2008

\begin{abstract}
Objective To describe the prevalence of nausea and vomiting during radiotherapy and to compare quality of life, psychological and functional status in patients experiencing or not experiencing nausea.
\end{abstract}

A. Enblom $\cdot$ S. Börjeson

Department of Medicine and Health Sciences,

Division of Nursing Science, Linköping University,

Linköping, Sweden

\section{Hammar}

Department of Clinical and Experimental Medicine,

Division of Obstetrics and Gynecology, Linköping University,

Linköping, Sweden

\section{S. Börjeson}

Centre of Surgery and Oncology, Department of Oncology,

Linköping University Hospital,

Linköping, Sweden

\section{B. Bergius Axelsson}

Department of Oncology, Karolinska University Hospital,

Stockholm, Sweden

G. Steineck

Department of Oncology,

Division of Clinical Cancer Epidemiology, Sahlgrenska Academy,

Gothenburg, Sweden

G. Steineck

Department of Oncology and Pathology,

Division of Clinical Cancer Epidemiology, Karolinska Institute,

Stockholm, Sweden

\section{A. Enblom}

Vårdal Institute,

Lund, Sweden

\section{A. Enblom ( $\square)$}

IMH omvårdnad,

BSP plan 13, Hälsouniversitetet,

SE-581 85 Linköping, Sweden

e-mail: anna.enblom@imv.liu.se
Materials and methods A cross-sectional selection of 368 cancer patients treated with radiotherapy answered a questionnaire $(=93 \%$ answering rate) regarding nausea, vomiting, actual use of and interest in antiemetic treatment, quality of life and psychological and functional status during the preceding week of radiotherapy. Mean age was 60 years and $66 \%$ were women.

Main results Nausea was experienced by 39\% (145) and vomiting by $7 \%$ (28) of patients in general, by $63 \%$ in abdominal or pelvic fields and by $48 \%$ in head/neck/brain fields. Abdominal/pelvic field (Relative risk (RR) 2.0), age $\leq 40$ years (RR 1.9) and previous nausea in other situations (RR 1.8) implied an increased risk for nausea. Antiemetics were used by $17 \%$ and $78 \%$ were interested in or wanted more information about acupuncture treatment against nausea. Of the 145 nauseous patients only $25 \%$ felt that antiemetics had helped them and $34 \%$ would have liked additional treatment, although the nausea intensity was mild in $72 \%$. The nauseous patients reported lower well-being and quality of life, lower satisfaction with aspects of daily living and more frequent anxiety and depressed mood than the patients without nausea. Conclusions Of all patients undergoing radiotherapy, 39\% experienced nausea and one third of them would have liked more treatment against the nausea. This study stresses the importance to identify and adequately treat patients with increased risk for nausea related to radiotherapy.

Keywords Antiemetics · Daily living · Risk factors . Vomiting · Quality of life

\section{Introduction}

Nausea is one of the most widely feared symptoms and it is ranked among the most incapacitating side effects experienced during cancer treatment $[6,22,50]$. Many studies 
have focused on nausea induced by chemotherapy, but less attention has been addressed to radiotherapy-induced nausea $[31,52]$. Little is documented about how satisfied patients are with their antiemetic treatment and how nauseated patients experience quality of life and the daily life situation during radiotherapy.

The frequency of nausea during radiotherapy varies depending on the site being irradiated. For example, total body irradiation causes nausea more often $(80-100 \%$ of patients) [46] than radiation to specific fields $(39 \%$ in general) [25]. Also, single dose treatments more often $(80 \%)$ lead to nausea albeit with shorter duration than fractionated treatments $[16,17]$. Studies regarding radiotherapy-induced nausea have focused on evaluating a specific antiemetic drug, mostly in total body irradiation, half body irradiation or upper abdomen irradiation rather than observing the prevalence of nausea and vomiting in radiotherapy patients in general, treated in a normal clinical setting [31]. That limits the application of those study results to a general population undergoing radiotherapy. Some exceptions exist; for example, an Italian study by IGARR [25], showing that $39 \%$ of 914 radiotherapy patients in general experienced nausea or vomiting. The prevalence varied between 19\% in fields including the skin or extremities to $71 \%$ in upper abdominal fields. The risk for nausea and vomiting increased when the size of radiotherapy field was over $400 \mathrm{~cm}^{2}$ [25]. Other risk factors than radiotherapy treatment-related variables, have not been widely explored as factors in radiotherapy-induced nausea. IGARR [25] found that previous chemotherapy increased the emetic risk. However, risk factors associated with chemotherapy-induced nausea may also be applicable for radiotherapy-induced nausea $[2,17,23]$. Lower age, female gender, low alcohol intake, anxiety and previous experience of nausea in other situations such as previous chemotherapy indicate an increased risk for chemotherapy-induced nausea $[9,13,44]$ and are factors that would be interesting to evaluate further as factors in radiotherapy-induced nausea.

For radiotherapy-induced nausea and vomiting there are international antiemetic guidelines [17, 27, 31] but how they are transferred into daily clinical practice and how satisfied the patients are with their antiemetic treatment is not well investigated. Some clinics offer non-pharmacological methods such as acupuncture as a complement to antiemetics [14] but the interest in undergoing acupuncture treatment in patients with radiotherapy-induced nausea has not, to our knowledge, been studied.

Studies have shown that chemotherapy-induced nausea and vomiting reduce well-being [11], quality of life [3, 30, $32]$, performance of daily activities [30, 33, 34], ability to socially interact [30] and increases anxiety and low mood [43]. However, [30] radiotherapy-induced nausea is generally less frequent and less severe than chemotherapy-induced nausea [42] and it is not known to what extent these findings are also valid for patients with nausea during radiotherapy.

The objective of this study was to describe the prevalence of nausea and vomiting, the use of and satisfaction with treatment against nausea, and to identify risk factors for nausea during radiotherapy. Another objective was to compare quality of life and psychological and functional status as reported by patients experiencing nausea and by those not experiencing nausea.

\section{Materials and methods}

A descriptive epidemiological design [49] was used. The study has been approved by the Regional Ethics Committees.

\section{Participants}

A cross-sectional selection was made on four different days at the radiotherapy departments of two Swedish University hospitals, 2 days at each hospital. Both hospitals cover a region in which patients live in cities as well as rural areas. Potential participants were identified by research nurses at each department and received written information about the study. The study cohort consisted of all individuals 18 years or older, irrespective of cancer diagnosis, who received curative or palliative radiotherapy, giving informed consent, could communicate in Swedish and understood the procedure of the study. The exclusion criteria were any kind of illness of such severity that the patient could not manage participating in the study. The study intended to describe the ordinary clinical situation. Antiemetics were prescribed according to the normal clinical routines by the patients' oncologist.

\section{Study variables}

Clinical data (cancer diagnosis, irradiated field and dose) were extracted from the patients' medical record and data from a study-specific questionnaire were collected. The questionnaire was in 20 radiotherapy patients, not included in this study, tested for face-validity as follows: the questionnaire was developed through interviews, was filled in by the 20 patients and was then changed until the investigator was certain that all the questions were correctly understood and could be answered appropriately.

Questions regarding demographic data, for example age, level of education, marital and work status were included (Table 2). Questions regarding experience of previous nausea when travelling by car, boat or plane, nausea related to unpleasant smells or sights, in worrying situations, during pregnancy and during eventual previous chemotherapy and radiotherapy were also included. 
The questionnaire also included questions about the week preceding the day on which the questionnaire was given. The prevalence and intensity of nausea were evaluated using the question: "Have you experienced nausea during the past week?", which was answered on a four-level category scale: "No, not at all", "Yes, a little, "Yes, moderately", "Yes, much". The patient's subjective opinion regarding the reason for experiencing nausea was expressed using structured answering categories with a place for additional open answers. The number of vomiting episodes was graded on a three-level category scale: "No vomiting at all", "Fewer than five vomiting episodes", "Five or more vomiting episodes". The use of pharmacological or non-pharmacological antiemetic treatment was registered. The satisfaction with the antiemetic treatment was measured with two questions. The first was: "If you received antiemetic treatment during the past week, have you been helped by the treatment?" with the answering categories: "Not relevant, I have not experienced nausea", "Yes, I have been much helped", "Yes, I have been moderately helped", "Yes, I have been helped a little", "No, I have not been helped at all" and "No, I did not receive any antiemetics at all". The second question was "Would you like to receive additional antiemetic treatment?" with the answering categories "No, nausea is not a problem", "No, I have chosen not to take antiemetics", "Yes, I would like to receive additional treatment" and "Yes, I have not received any antiemetic treatment at all". A question about willingness to try acupuncture was phrased: "If it in the future was possible to choose acupuncture for the treatment of nausea, would you like to try acupuncture?". The answering categories were: "Yes, without any pharmacological antiemetics", "Yes, as a complement to antiemetics" "I am not sure, I would like to receive more information" and "No, probably not".

Other questions covered "physical and psychological condition" (five items), "quality of life" (one item) and "satisfaction with the daily living situation" (seven items) during the past week. For details, see Table 1.

\section{Procedure}

The patients received the questionnaire at their ordinary radiotherapy treatment session, answered it in private and sent it to the study coordinator, using a prepaid envelope. One reminder by phone was made if the patients had not sent in the questionnaire within 2 weeks after first receiving it. In order to avoid bias when answering the questionnaire the involved radiotherapy health care professionals did not see the completed questionnaires.

\section{Statistical methods}

Descriptive statistics: number $(n)$, proportion (\%), mean $(m)$, standard deviation (sd), median (md), 25th and 75th percentile and range, were calculated separately for patients experiencing nausea (the four-level nausea question categorized: "Yes, a little, "Yes, moderately" and "Yes, much") and without nausea ("No, not at all"). We selected possible risk factors for nausea (i.e. experiencing nausea previously in other situations, clinical and demographic data; see Table 2) and calculated nausea prevalence ( $n, \%)$, relative risk (RR) and $95 \%$ confidence intervals for the different subgroups compared to a reference group. The reference

Table 1 Example of variables included in the data collection

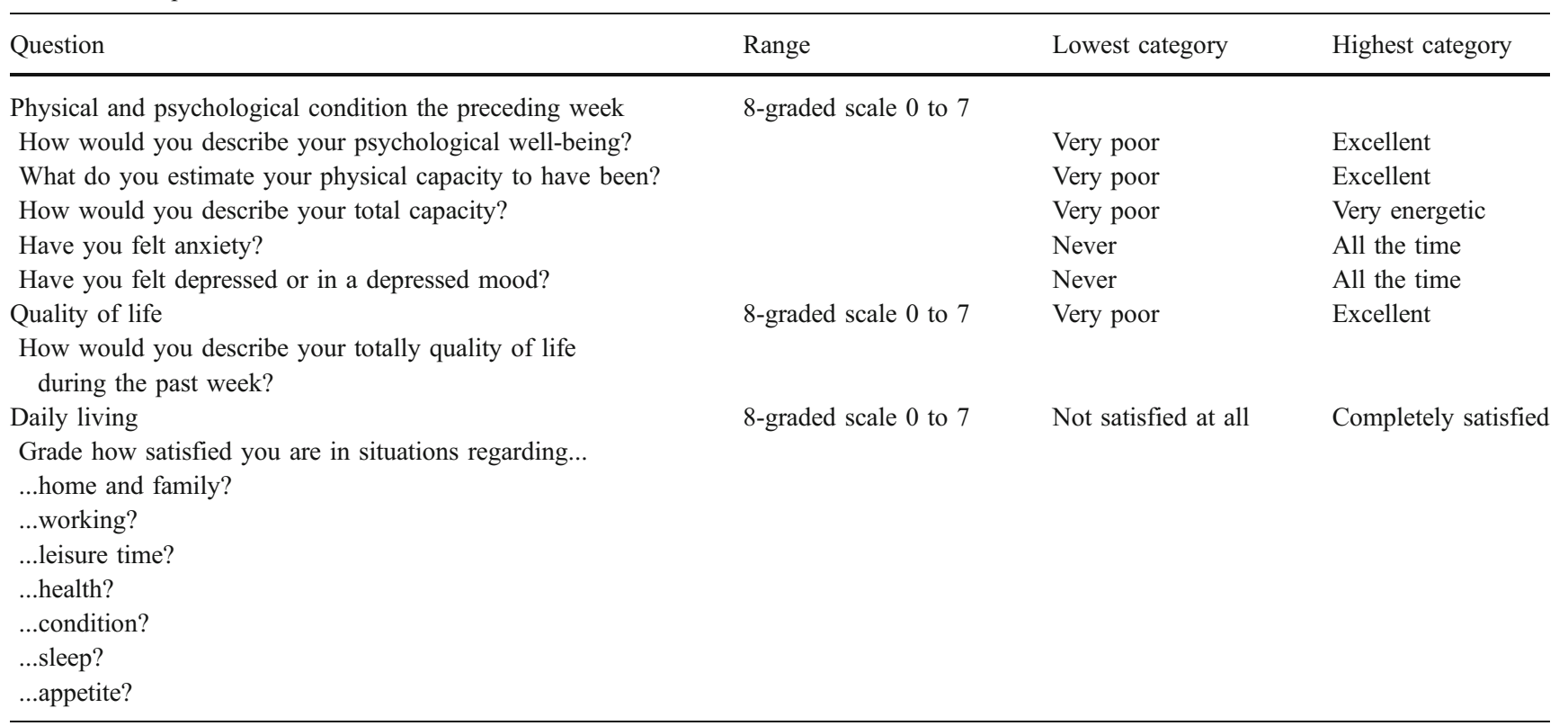


Table 2 Patient characteristics and relative risks for nausea

\begin{tabular}{|c|c|c|c|c|}
\hline Variables & Totally & Experiencing nausea & Free from nausea & $\mathrm{RR}(95 \% \mathrm{CI})$ \\
\hline All patients & 368 & $145(39)$ & $223(61)$ & \\
\hline \multicolumn{5}{|l|}{ Irradiated sites } \\
\hline Breast & 160 & $50(31)$ & $110(69)$ & 1.0 (Ref.) \\
\hline Abdomen or pelvis & 62 & $39(63)$ & $23(37)$ & $2.0(1.5-2.7)$ \\
\hline Mediastinum & 25 & $9(36)$ & $16(64)$ & $1.2(0.7-2.0)$ \\
\hline Head and Neck & 37 & $17(46)$ & $20(54)$ & $1.5(1.0-2.2)$ \\
\hline Prostate or bladder & 55 & $18(33)$ & $37(67)$ & $1.0(0.7-1.6)$ \\
\hline Brain & 22 & $10(45)$ & $12(55)$ & $1.5(0.9-2.4)$ \\
\hline Other, ex. extremities & 7 & $2(29)$ & $5(71)$ & $0.9(0.3-3.0)$ \\
\hline Accumulated dose (Gray): m, SD & $24.8 \pm 14.4$ & $23.8 \pm 13.8$ & $25.4 \pm 14.7$ & \\
\hline \multicolumn{5}{|l|}{ Gender } \\
\hline Male & $125(34)$ & $47(38)$ & $78(62)$ & $0.9(0.7-1.2)$ \\
\hline Female & $243(66)$ & $98(40)$ & $145(60)$ & 1.0 (Ref.) \\
\hline Age years: m, SD & $60.0 \pm 12.2$ & $57.9 \pm 13.7$ & $61.4 \pm 10.8$ & \\
\hline Range & $19-86$ & $19-86$ & $19-86$ & \\
\hline $19-40$ & $23(6)$ & $14(61)$ & $9(39)$ & $1.9(1.3-2.7)^{\circ}$ \\
\hline $41-60$ & $165(45)$ & $72(44)$ & $93(56)$ & $1.3(1.0-1.7)$ \\
\hline $61-86$ & $180(49)$ & $59(33)$ & $121(67)$ & 1.0 (Ref.) \\
\hline \multicolumn{5}{|l|}{ Country of birth } \\
\hline Sweden & $320(87)$ & $120(38)$ & $200(62)$ & 1.0 (Ref.) \\
\hline Other country & $48(13)$ & $25(52)$ & $23(48)$ & $1.4(1.0-1.9)$ \\
\hline Marital status & $367^{\mathrm{b}}$ & $144^{\mathrm{b}}$ & & \\
\hline Married/living together & $261(71)$ & $96(37)$ & $165(63)$ & 1.0 (Ref.) \\
\hline Not married/living alone & $106(29)$ & $48(45)$ & $58(55)$ & $1.2(0.9-1.6)$ \\
\hline Education & $367^{\mathrm{b}}$ & & $222^{\mathrm{b}}$ & \\
\hline University & $120(33)$ & $56(47)$ & $64(53)$ & $1.3(1.0-1.7)$ \\
\hline Primary/secondary school & $247(67)$ & $89(36)$ & $158(64)$ & 1.0 (Ref.) \\
\hline Religion & $365^{\mathrm{b}}$ & $143^{\mathrm{b}}$ & & \\
\hline Christian/other religion & $306(84)$ & $113(37)$ & $193(63)$ & 1.0 (Ref.) \\
\hline Non-believer & $59(16)$ & $30(51)$ & $29(49)$ & $1.4(1.0-1.8)$ \\
\hline \multicolumn{5}{|l|}{ Other illness } \\
\hline Yes & $248(57)$ & $105(42)$ & $142(67)$ & $1.3(0.9-1.7)$ \\
\hline No & $120(33)$ & $40(33)$ & $80(67)$ & 1.0 (Ref.) \\
\hline \multicolumn{5}{|l|}{ Nausea in previous chemotherapy } \\
\hline Not relevant, no previous chemotherapy & $293(80)$ & $114(39)$ & $179(61)$ & 1. 0 (Ref.) \\
\hline Yes & $20(5)$ & $9(45)$ & $11(55)$ & $1.2(0.7-1.9)$ \\
\hline No & $55(15)$ & $22(40)$ & $33(60)$ & $1.0(0.7-1.5)$ \\
\hline Nausea during pregnancy & $365^{\mathrm{b}}$ & $143^{\mathrm{b}}$ & & \\
\hline No & $241(66)$ & $90(37)$ & $151(63)$ & 1.0 (Ref.) \\
\hline Yes & $124(34)$ & $53(43)$ & $71(57)$ & $1.1(0.8-1.5)$ \\
\hline Previous nausea in any situation & $366^{\mathrm{b}}$ & $144^{\mathrm{b}}$ & $222^{\mathrm{b}}$ & \\
\hline No & $114(31)$ & $29(25)$ & $85(75)$ & 1.0 (Ref.) \\
\hline Yes & $252(69)$ & $115(46)$ & $137(54)$ & $1.8(1.3-2.5)^{2}$ \\
\hline $\mathrm{N}$ of previous nausea indicators, $\mathrm{Md}, 25 \mathrm{th}-75$ th percentile & $1,0-2$ & $1,1-4$ & $1,0-2$ & \\
\hline $0-4$ indicators & $325(88)$ & $119(37)$ & $206(63)$ & Ref. \\
\hline $5-9$ indicators & $43(12)$ & $26(60)$ & $17(40)$ & $1.7(1.2-2.2)$ \\
\hline
\end{tabular}

$R R$ Relative risk, $C I 95 \%$ confidence interval, $M$ mean, $S D$ one standard deviation, Ref. reference group with the lowest prevalence of nausea ${ }^{a}$ Statistical significant increased risk for nausea compared to the reference group

${ }^{\mathrm{b}}$ Number who answered the question

group (RR 1.0) was defined as the subgroup with the lowest prevalence of nausea. One exception from this procedure was made when analyzing irradiated sites. The breast region was chosen as reference group since the category with the lowest prevalence of nausea ("Other" region) consisted of only seven patients. Variables that could have been affected by nausea, for example anxiety, depressed mood, quality of life and satisfaction with the daily living situation, were compared between patients with and without nausea using Mann-Whitney $U$ test. The statistical analyses 
were based on all the answer categories (null to seven) for each question seen in Table 1, but the answer categories were categorized (null to two, three to five and six to seven) when presented in Fig. 1. The level of statistical significance was set at a confidence interval not including 1 , or $p<0.03$, to adjust for multiple testing to avoid type- 1 errors.

\section{Results}

During the four days of data collection, 476 patients were scheduled to have radiotherapy. Of those, 58 were too ill to participate and 22 did not give their informed consent, leaving 396 who were included in the study. Twenty-eight patients did not answer the questionnaire after one reminder while 368 answered the questionnaire (93\%), 125 men and 243 women. For characteristics of the patients, see Table 2. A typical patient included in the study was a 60-year-old woman who received radiotherapy to the breast region for an accumulated dose of 24.8 Gray, not combined with chemotherapy.

\section{Risk factors for nausea}

Among the 368 patients, 145 (39\%) experienced nausea during the past week of radiotherapy. The factors associated with an increased risk for experiencing nausea were radiation over pelvic or abdominal fields (63\%), age younger than 40 years $(61 \%)$ and previous experience of nausea in other situations (Table 2).

Nausea and vomiting

The nausea intensity was graded as "little" in $104(72 \%)$ of those 145 patients who experienced nausea the past week. There was a greater percentage of patients treated over abdominal or pelvic fields who experienced at least moderate nausea ( $n=15$ of $62,24 \%$ ) (Table 3 ) than among the nauseated patients treated over other fields $(n=26$ of $306,8 \%$ ), RR 2.8, 95\% C.I. $1.6-5.1$.

Ninety-five of the 145 nauseated patients expressed their own opinions concerning the reasons for experiencing nausea: $77(81 \%)$ thought that radiotherapy was the only reason while eighteen $(19 \%)$ patients mentioned other factors that could have produced nausea-pharmacological treatment (eight), the tumor itself (three), chemotherapy (three), another disease (three) and travelling (one).

Of the 368 radiotherapy patients, $28(7 \%)$ had vomited during the preceding week, with higher prevalence in patients treated over the abdominal or pelvic fields $(n=9$, 15\%; RR 2.3, CI 1.1-4.9 (Table 3).

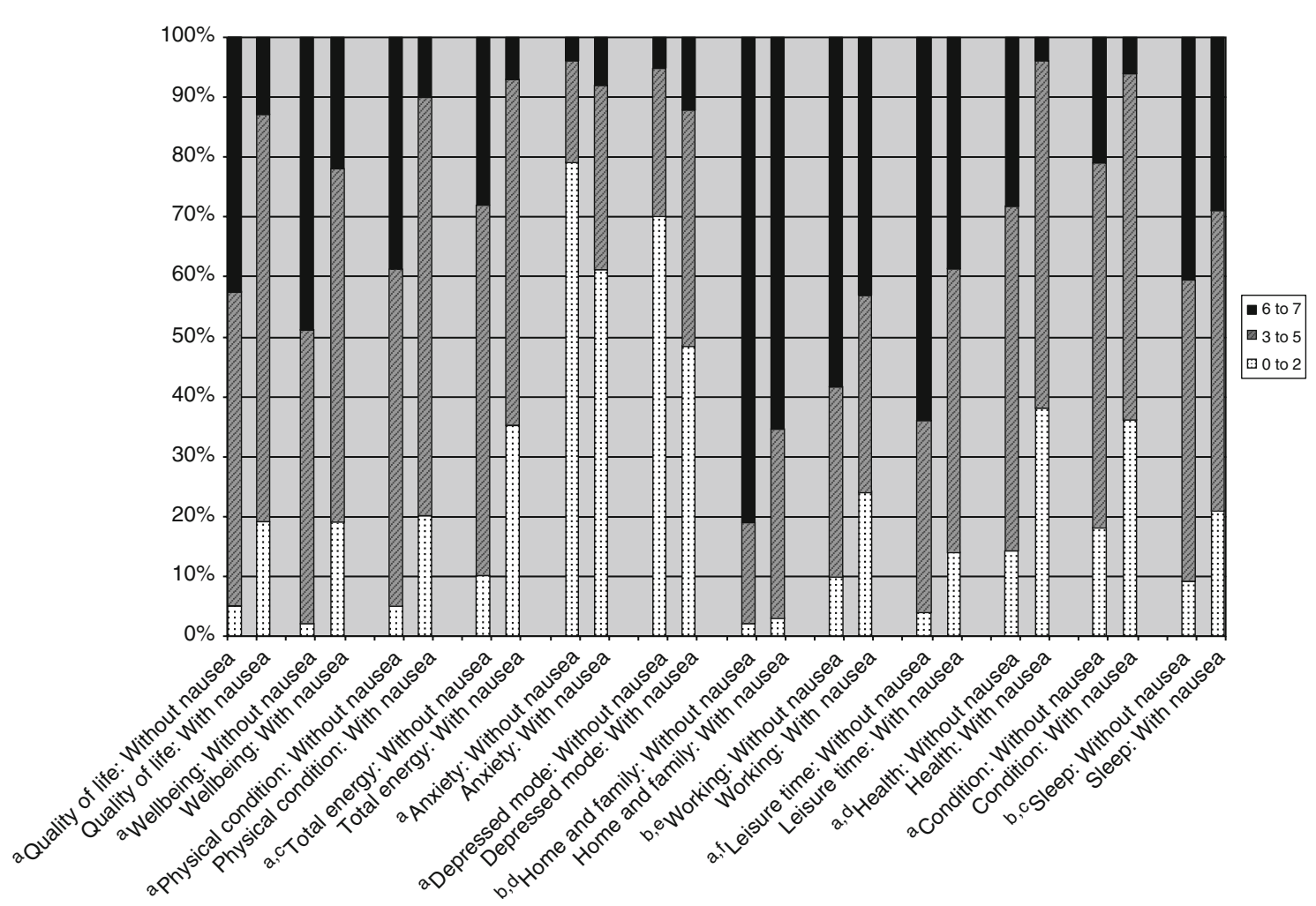

Fig. 1 Self-assessed physical and psychological outcomes, global quality of life and satisfaction in daily living situations in patients with and without nausea $(n=368)$. Assessments on an 8 -grade scale, $0=$ lowest possible and 7 highest possible. Percentages of patients without nausea $(n=223)$ and with nausea $(n=145)$ last week. a $P<0.001$ b $P=0.001$ c $n=367, d n=366, e n=305, f n=358$ 


\section{Treatment against nausea}

Of all the 368 patients, 61 (17\%) had taken some kind of antiemetics and $16(4 \%)$ had received $5-\mathrm{HT}_{3}$ receptor antagonists during the past week of radiotherapy.

Of the 145 patients who experienced nausea during the preceding week, $45(31 \%)$ had taken at least one antiemetic drug, $11(8 \%)$, had taken two drugs and one patient had taken three drugs. A fourth $(n=36)$ of the nauseous patients stated that they had received antiemetics that had helped them at least to a moderate extent. Fifty (34\%) of the 145 nauseous patients would have liked additional treatment against their nausea while $58(40 \%)$ had decided not to take antiemetics (Table 4).

The use of antiemetics was more frequent in the 62 patents who were treated over the abdominal or pelvic fields compared to the patients treated over other fields; 28 $(45 \%)$ of the 62 patients had been taking some kind of antiemetics during the preceding week and $6(10 \%)$ had received a $5-\mathrm{HT}_{3}$ receptor antagonists.

None of the 368 patients reported use of any nonpharmacological treatment against nausea. Forty percent (145/361 who answered the question) said that they would like to try acupuncture to treat nausea, if acupuncture was made available-67 (19\%) without any pharmacological antiemetics and $78(22 \%)$ as a complement to antiemetics. One hundred thirty-six (38\%) were not sure and asked for more information about the method while $80 \quad(22 \%)$ answered that they probably not would try acupuncture.

Quality of life, physical and psychological conditions and satisfaction with aspects of daily living

The 145 patients who experienced nausea rated their quality of life, physical capacity, well-being and energy level lower

Table 3 Prevalence of nausea and vomiting during the past week

\begin{tabular}{lll}
\hline & Totally, $n(\%)$ & $\begin{array}{l}\text { Abdominal or pelvic } \\
\text { fields, } n(\%)\end{array}$ \\
\hline $\begin{array}{l}\text { Number of patients } \\
\text { Nausea }\end{array}$ & 368 & 62 \\
Md & Little & Little \\
25th-75th percentile & Little-little & Little-moderate \\
No & $223(61)$ & $23(37)$ \\
Yes, little & $104(28)$ & $24(39)$ \\
Yes, moderate & $27(7)$ & $11(18)$ \\
Yes, much & $14(4)$ & $4(6)$ \\
Vomiting & $340(92)$ & $53(85)$ \\
No & $20(5)$ & $6(10)$ \\
Yes, $<5$ episodes & $8(2)$ & $3(5)$ \\
Yes, $\geq 5$ episodes & & \\
\hline
\end{tabular}

Md median
Table 4 Antiemetics in patients experiencing nausea during the past week $(n=145)$

\begin{tabular}{ll}
\hline Variable & Number (\%) \\
\hline Antiemetics last week & \\
No & $88(61)$ \\
Yes & $57(39)$ \\
Type of antiemetics & \\
Anti-histamines & 71 \\
Dopamine receptor antagonists & 28 \\
Serotonin (5TH ${ }^{3}$ )-receptor antagonists & 26 \\
Corticosteroids & 12 \\
Neuroleptics with antiemetic effects & 3 \\
Combinations of antiemetic types & 2 \\
Anti-histamines and serotonin (5TH $\left.{ }^{3}\right)$-receptor & 2 \\
antagonists & \\
Dopamine receptor antagonists and serotonin & 5 \\
(5TH ${ }^{3}$ )-receptor antagonists & \\
Corticosteroids and serotonin (5TH $\left.{ }^{3}\right)$-receptor & 1 \\
antagonists & \\
Anti-histamines and dopamine receptor antagonists & 2 \\
Dopamine receptor antagonists and & 1 \\
neuroleptics & \\
Anti-histamines, dopamine receptor antagonists & 1 \\
and serotonin (5TH $\left.{ }^{3}\right)$-receptor antagonists & $174^{\mathrm{b}}$ \\
Had help from medications & $96(67)$ \\
Experiencing nausea, did not receive antiemetics & $27(19)$ \\
To a large extent & $9(6)$ \\
To a moderate extent & $10(7)$ \\
To a little extent & $1(1)$ \\
Not at all & $1(1)$ \\
Do not know & $141^{\mathrm{b}}$ \\
Ask for additional antiemetic treatment & $33(23)$ \\
No, nausea is not a problem & $58(41)$ \\
No, have chose to not take antiemetics & $33(23)$ \\
Yes, ask for additional treatment & $17(12)$ \\
Yes, ask for treatment, have not received & \\
any treatment & \\
\hline
\end{tabular}

${ }^{\mathrm{a}}$ The number of antiemetics taken was 71 , because 12 patients received more than one drug (range 1-3)

${ }^{\mathrm{b}}$ Number who answered the question

and had more frequent anxiety and depressed mood compared to the 223 patients who had been free from nausea during the week (Fig. 1). A smaller proportion $(13 \%)$ of the patients who experienced nausea ranked their quality of life as very high or high (6-7 on the scale) compared to $43 \%$ of the patients without nausea. Approximately a fourth of the patients who experienced nausea rated their well-being as very good or good (6-7 on the scale) compared to half of the patients who were free from nausea. Approximately half of the nauseous patients (51\%) and a third $(30 \%)$ of the patients free from nausea graded three or more (out of maximum seven) on the question covering depressed mood. The patients who reported nausea also graded lower satisfaction with all aspects of 
the daily living situation, seen in Fig. 1, compared to the patients without nausea.

\section{Discussion}

This study showed that of all patients undergoing radiotherapy, during a typical week of treatment $39 \%$ experienced nausea and $7 \%$ vomited. Radiotherapy targeted to the pelvic or abdominal field indicated an increased risk of nausea $(63 \%)$ and so too did an age younger than 40 years and prior experience of nausea. Of those patients who experienced nausea, only a fourth felt that antiemetics had helped them at least moderately while a third would have liked additional antiemetic treatment. The patients who experienced nausea reported lower satisfaction with aspects of daily living, lower well-being and quality of life, lower total energy and physical condition and experienced more frequent anxiety and depressed mood than the patients without nausea.

The findings that during a typical week of radiotherapy, $39 \%$ patients in general, $63 \%$ of the patients treated over abdominal or pelvic fields and $46 \%$ of patients treated over head, neck or brain fields experienced nausea were quite similar he findings reported by IGARR [25]. IGARR found that $39 \%$ of patients in general, $71 \%$ treated over abdominal fields and approximately $40 \%$ treated over the brain, head and neck region experienced nausea or vomiting during their radiotherapy period. Other previous findings on the prevalence of radiotherapy-induced nausea are based on studies evaluating the effect of antiemetics. Mystakidou et al. [36] included 288 radiotherapy patients and found that nausea was experienced by $58 \%$ of 50 patients irradiated over the abdominal field, $61 \%$ of 56 patients irradiated over the thoracic field, $64 \%$ of 47 patients irradiated over the cerebral region. It is interesting to note that irrespective of the radiated field, the prevalence was rather high. Maranzano et al. [31] divided the emetic risk into four levels; high risk $(>90 \%)$ in total body irradiation, moderate risk (60-90\%) in upper abdomen, low risk (30-59\%) in lower thoracic and pelvic region and minimal risk $(<30 \%)$ in cranium, breast, extremities and head and neck field. Our study, as well as those from IGARR [25] and Mystakidou et al. [36] may suggest that the thoracic and pelvic fields should be classified as producing moderate risk instead of low risk and head, neck or brain field should be classified as low risk instead of minimal risk for nausea.

It has previously been shown that lower age is associated with an increased risk for chemotherapy-induced nausea [9, 13] and in our study, an age lower than 40 years indicated an increased risk also for radiotherapy-induced nausea. Earlier experience of nausea in any other situations, for example during previous chemotherapy, indicated an increased risk for nausea, which is in concordance with previous literature [16, 17, 25].

One third of the nauseous patients would have liked additional antiemetic treatment, indicating that in daily radiotherapy practise, health care professionals may underestimate nausea, in line with several earlier studies $[18,23$, 25]. Only one fourth of the patients who experienced nausea during radiotherapy felt that antiemetics had helped them at least moderately, which is a lower level of satisfaction than with antiemetic treatment during chemotherapy. Bosnjak et al. [8] found that a large majority (88\%) of 136 chemotherapy patients stated that they were satisfied with their antiemetic treatment. The control of symptoms and satisfaction with the antiemetic treatment can be considered to be important goals of care, since Bosnjak et al. showed that patients who were dissatisfied with their antiemetic treatment experienced lower quality of life. Uncontrolled nausea and vomiting are risk factors for development of anticipatory nausea, which typically occurs after a previous negative experience of nausea and can continue for several years [23]. The finding that many patients considered their antiemetic treatment insufficient may, besides under-treatment, be related to use of less effective antiemetics. The proportion of all our study patients who received antiemetics (17\%) was about the same proportion and $14 \%$ as reported by others $(15 \%)[15$, $25]$ but the proportion was in our study rather low also in patients irradiated over abdominal/pelvic fields, especially regarding use of $5-\mathrm{HT}_{3}$ antagonists. The oncologists treating patients in our study may have positive clinical experiences from other types of antiemetics than $5 \mathrm{HT}_{3}$ receptor antagonists. $5 \mathrm{HT}_{3}$-receptor antagonists are much more expensive than other types of antiemetics. In some cases, a wish to reduce prescription cost [1] may result in the choice of a cheaper alternative. The low utilisation of $5-\mathrm{HT}_{3}$ antagonists is not in line with evidence-based suggestions for this patient group, both in older [19, 21, $35]$ and in more recently updated antiemetic guidelines based on randomised controlled studies [17, 27, 31]. During upper abdominal irradiation, it has been shown that a $5-\mathrm{HT}_{3}$ antagonist given prophylactic ( $43 \%$ had nausea) was more effective than placebo (58\% had nausea) [28] and was more effective than corticosteroids only [40]. A combined treatment with a $5-\mathrm{HT}_{3}$ antagonist and corticosteroids given as prophylaxis had additional effects compared to a $5-\mathrm{HT}_{3}$ antagonist combined with placebo (77\% versus $88 \%$ experienced nausea or vomiting) [37]. $5 \mathrm{HT}_{3}$-receptor antagonists given prophylactic (50\% had nausea) was more effective than $5 \mathrm{HT}_{3}$-receptor antagonists rescue $(65 \%$ had nausea) [36]. There are differences between the antiemetic guidelines regarding when and how $5-\mathrm{HT}_{3}$ antagonists should be prescribed. Abdominal and pelvic fields are 
classified as moderate risk for nausea by ASCO (American Association of Clinical Oncology) [27] but pelvic fields as low risk by MASCC (Multinational Association of Supportive Care in Cancer) [31]. MASCC for low risk suggests prophylaxis or rescue with $5-\mathrm{HT}_{3}$ antagonists and for moderate risk prophylaxis with $5-\mathrm{HT}_{3}$ antagonists, possibly combined with corticosteroids. ASCO for low as well as for moderate risk suggests prophylaxis with a $5-\mathrm{HT}_{3}$ antagonist or in some patients a dopamine receptor antagonist, without corticosteroids [27]. It seems like the oncologists have followed MASCC's emesis risk-classification (pelvis= low risk) but none of the antiemetic guidelines [27, 31]. Eighty-eight of the nauseous patients $(61 \%)$ did not take any antiemetics at all, which is not in concordance to any of the guidelines. We can only hypothetically discuss the plausible reasons for this under-treatment. As already mentioned, it may be caused by an underestimation of the problem; the patients in daily clinical practice may not complain about the nausea for reasons such as "wanting to be nice to the therapist" while the health care professionals do not ask if the patient is bothered by nausea. Health care professionals may estimate the nausea-risk as low or minimal, or they may think that the patients will be nauseous if they are asked about nausea occurrence. Additional reasons for the low utilisation of antiemetics in our study may be that the nausea was perceived as mild in most patients $(72 \%)$ and that $40 \%$ of the nauseous patients stated they had decided not to take antiemetics. We have no data on the reasons for choosing not to take antiemetics. Those $40 \%$ may have been proposed or even prescribed antiemetics, but have chosen not to take it; or they may not have been properly informed about their risk for nausea and thus not offered antiemetics. Hypothetically, one reason may be that the patients were afraid of side effects related to antiemetic consumption. In a study of 453 American patients with cancer, the most common reasons for using complementary medicine, in which acupuncture was included, was a desire to feel hopeful (73\%), a wish to use non-toxic treatments $(49 \%)$, and to control decisions regarding their medical care (44\%) [41]. The interest shown for acupuncture treatment against nausea, seen in our study, emphasizes the relevance to determine if acupuncture is effective in patients who, as a complement to antiemetics, want to try non-pharmacological treatments against nausea during radiotherapy.

Although nausea was mild in $72 \%$ of the nauseated patients, the nauseated patients reported lower satisfaction with aspects of daily living, lower well-being and quality of life, lower total energy and physical condition and more frequent anxiety and depressed mood than the patients without nausea. Nausea has, in studies concerning chemotherapy-induced nausea, seemed to cause substantial physical, psychological and functional distress for the patient [3,
$18,32-34,39,43]$. Previous findings regarding the impact of radiotherapy-induced nausea on quality of life are based on studies evaluating antiemetics. Sykes et al. [51] found that emesis-related quality of life was higher in a group of 33 palliative radiated patients treated with $5 \mathrm{TH}_{3}$-receptor antagonists (30\% experienced nausea) compared to a control group including 33 patients treated with corticosteroids ( $72 \%$ experienced nausea). Global quality of life did in our study differ between patients with and without nausea but did not differ between the groups in the study by Sykes et al., nor between a group including 75 patients irradiated over upper abdomen treated with corticosteroids (30\% vomited or retched) compared to 76 patients receiving placebo pills (51\% vomited or retched) [26]. Radiotherapy induced nausea is commonly considered to be less problematic than post chemotherapy nausea [42], but our results indicate that also nausea during radiotherapy may affect the patients' daily life in several negative ways. The usually long duration of nausea [16] may be one conceivable explanation why patients with nausea, even if mild in intensity, felt poorer in so many ways compared to the patients free from nausea. Longer duration of nausea decreased well-being in patients receiving chemotherapy, even when nausea intensity was controlled for [11].

A strength in this study is the response rate to the questionnaire (93\%) which could be considered as very high compared to five Swedish nationwide postal questionnaires comprising a total of 4,009 invited cancer patients, individuals who have lost a family member in cancer and healthy population controls. The total mean response rate was $76 \%$ and varied for the patient groups from $77 \%$ to $88 \%$ [38]. Reasons for the high response rate in our study may be that the patients found the study valuable and the questionnaire relevant. In addition, one reminder by phone was made which is known to increase answering rate. Another strength is the inclusion of a wide variety of radiotherapy patients, not restricted to patients receiving treatment over a specific field or receiving a specific antiemetic agent. This indicates that our findings are valid to a general radiotherapy population treated with similar routines as in this study, but the radiotherapy treatment routines may differ in an international perspective. The similarities with previous findings regarding nausea incidence [25] support the validity of our findings. However, the lack of longitudinal information makes it impossible to describe the longitudinal history of nausea and antiemetics taken. We avoided bias [49] by informing patients that the health care professionals were not aware of the patients' answers. The construction and use of a studyspecific questionnaire has been described previously [4, 48]. The face-validation process made sure that the questions and the grading of answers were appropriate for this specific patient group. Nausea was measured with a 
category scale that is an established method to measure nausea and has been demonstrated to have good correlation with a visual analog scale [7, 10]. Several established instruments are available to measure quality of life, but they often include a large number of questions [47]. In this study, single-item questions were instead chosen to measure for example quality of life, anxiety, low mood and wellbeing in order to minimize the patient burden, as suggested by Sloan et al. [45] and Davaey et al. [12]. This kind of simple measurement has produced results similar to those from longer well-established questionnaires in measuring quality of life [5, 20, 24], anxiety [12] and mood status [38]. For measuring satisfaction with the daily living situation, the available established instruments were not suitable for our patient group. Lindeboom et al. [29] found 113 scales for measuring activities of daily living. Most of the scales are not intended for self assessment or are limited to specific patient groups (for example neurological disabilities) or measure basic mobility and self-care, which were not relevant for our patient group. Some methodology issues regarding causality in the study need to be discussed. For example, anxiety is known as a risk factor for chemotherapy-induced nausea $[9,13,44]$ and is also suggested to be a risk factor for radiotherapy-induced nausea. In our study, we do not have any longitudinal information regarding the anxiety, so the variable anxiety was excluded from the risk-analysis. We thus do not know if anxiety is a predictor of or a consequence for nausea.

This study implies that patients with increased risk for nausea should be identified and treated in advance, for example those with a history of nausea. If patients, despite preventive strategies, ask for additional antiemetic treatment or chose to not take antiemetics, it is reasonable to study if non-pharmacological treatments have effects on radiotherapy-induced nausea and vomiting.

Acknowledgments We thank the patients who took part in this study and the personnel at the radiotherapy departments of the University Hospital in Linköping and Karolinska Hospital in Stockholm, Sweden. We also thank Erik Onelöv for statistician support. This study was funded by The Vårdal Institute, The Vårdal Foundation and The County Council of Östergötland.

Open Access This article is distributed under the terms of the Creative Commons Attribution Noncommercial License which permits any noncommercial use, distribution, and reproduction in any medium, provided the original author(s) and source are credited.

\section{References}

1. Aapro M, Blower P (2005) 5-hydroxytryptamine type-3 receptor antagonists for chemotherapy-induced and radiotherapy-induced nausea and emesis: can we safely reduce the dose of administered agents? Cancer 104(1):1-18
2. Abdelsayed G (2007) Management of radiation-induced nausea and vomiting. Exp Hematol 35(4 suppl 1):34-36

3. Ballatori E, Roila F, Ruggeri B, Betti M, Sarti S, Soru G, Cruciani G, Di Maio M, Andrea B, Deuson RR (2007) The impact of chemotherapy-induced nausea and vomiting on health-related quality of life. Support Care Cancer 15(2):179-185

4. Bergmark K, Avall-Lundqvist E, Dickman PW, Henningsohn L, Steineck G (1999) Vaginal changes and sexuality in women with a history of cervical cancer. New Engl J Med 6:340(18):1383-1389

5. Bernhard J, Sullivan M, Hürny C, Coates AS, Rudenstam CM (2001) Clinical relevance of single item quality of life indicators in cancer clinical trials. Br J Cancer 84(9):1156-1165

6. de Boer-Dennert M, de Wit R, Schmitz PI, Djontono J, v Beurden V, Stoter G, Verweij J (1997) Patient perceptions of the sideeffects of chemotherapy: the influence of $5 \mathrm{HT}_{3}$ antagonists. $\mathrm{Br} \mathrm{J}$ Cancer 76(8): 1055-1061

7. Boogaerts JG, Vanacker E, Seidel L, Albert A, Bardiau FM (2000) Assessment of postoperative nausea using a visual analogue scale. Acta Anaesthesiol Scand 44(4):470-474

8. Bosnjak S, Radulović S, Nesković-Konstantinović Z, Mitrović L (2000) Patient statement of satisfaction with antiemetic treatment is related to quality of life. Am J Clin Oncol 23(6):575-578

9. Bremer K (1994) Individually risk-adapted antiemetic step therapy. Dtsch Med Wochenschr 119(16):598-604

10. Börjeson S, Hursti TJ, Peterson C, Fredrikson M, Fürst CJ, AvallLundqvist E, Steineck G (1997) Similarities and differences in assessing nausea on a verbal category scale and a visual analogue scale. Cancer Nurs 20(4):260-266

11. Börjeson S, Hursti TJ, Tishelman C, Peterson C, Steineck G (2002) Treatment of nausea and emesis during cancer chemotherapy. Discrepancies between antiemetic effect and well-being. J Pain Symptom Manage 24(3):345-358

12. Davey HM, Barratt AL, Butow PN, Deeks JJ (2007) A one-item question with a Likert or Visual Analogue Scale adequately measured current anxiety. J Clin Epidemiol 60(4):356-360

13. Doherty KM (1999) Closing the gap in prophylactic antiemetic therapy: patient factors in calculating the emetogenic potential of chemotherapy. Clin J Oncol Nurs 3(3):113-119

14. Ezzo JM, Richardson MA, Vickers A, Allen C, Dibble SL, Issell BF, Lao L, Pearl M, Ramirez G, Roscoe J, Shen J, Shivnan JC, Streitberger K, Treish I, Zhang G (2006) Acupuncture-point stimulation for chemotherapy-induced nausea or vomiting. Cochrane Database Syst Rev. April 19 (2):CD002285

15. Feyer P, Titlbach O, Wilkinson J, Budach V (1996) Gastrointestinal reactions in radiotherapy (abstract 100). Support Care Cancer 4:249

16. Feyer PC, Stewart AL, Titlbach OJ (1998) Aetiology and prevention of emesis induced by radiotherapy. Support Care Cancer 6(3):253-260

17. Feyer PCh, Maranzano E, Molassiotis A, Clark-Snow RA, Roila F, Warr D, Olver I (2005) Radiotherapy-induced nausea and vomiting (RINV): antiemetic guidelines. Support Care Cancer 13 (2):122-128

18. Foubert J, Vaessen G (2005) Nausea: the neglected symptom? Eur J Oncol Nurs 9(1):21-32

19. Goldsmith B (2003) Antiemetic patterns of care for radiotherapy induced nausea and vomiting (Abstract 2975). Am Soc Clin OncolASCO 22:740

20. Gough IR, Furnival CM, Schilder L, Grove W (1983) Assessment of the quality of life of patients with advanced cancer. Eur J Cancer Clin Oncol 19(8):1161-1165

21. Gralla RJ, Osoba D, Kris MG, Kirkbride P, Hesketh PJ, Chinnery LW, Clark-Snow R, Gill DP, Groshen S, Grunberg S, Koeller JM, Morrow GR, Perez EA, Silber JH, Pfister DG (1999) Recommendations for guidelines for the use of antiemetics: evidencebased, clinical practice guidelines. J Clin Oncol 17(9):2971-2994 
22. Griffin AM, Butow PN, Coates AS, Childs AM, Ellis PM, Dunn SM, Tattersall MH (1996) On the receiving end. V: patient perceptions of the side-effects of cancer chemotherapy in 1993. Ann Oncol 7(2):189-195

23. Horiot JC, Aapro M (2004) Treatment implications for radiationinduced nausea and vomiting in specific patient groups. Eur $\mathrm{J}$ Cancer 40(7):979-987

24. Hürny C, Bernhard J, Coates A, Peterson HF, Castiglione-Gertsch M, Gelber RD, Rudenstam CM, Collins J, Lindtner J, Goldhirsch A, Senn HJ (1996) Responsiveness of a single-item indicator versus a multi-item scale: assessment of emotional well-being in an international adjuvant breast cancer trial. Med Care 34(3):234-248

25. IGARR (the Italian Group for Antiemetic Research in Radiotherapy) (1999) Radiation-induced emesis: a prospective observational multicenter Italian trial. Int J Radiat Oncol Biol Phys 44(3):619-625

26. Kirkbride P, Bezjak A, Pater J, Zee B, Palmer MJ, Wong R, Cross P, Gulavita S, Blood P, Sun A, Dundas G, Ganguly PK, Lim J, Chowdhury AD, Kumar SE, Dar AR (2000) Dexamethasone for the prophylaxis of radiation-induced emesis: a National Cancer Institute of Canada Clinical Trials Group Phase III Study. J Clin Oncol 18(9):1960-1966

27. Kris MG, Hesketh PJ, Somerfield MR, Feyer P, Clark-Snow R, Koeller JM, Morrow GR, Chinnery LW, Chesney MJ, Gralla RJ, Grunberg SM (2006) American Society of Clinical Oncology guideline for antiemetics in oncology: update 2006. J Clin Oncol 24(18):2932-2947

28. Lanciano R, Sherman DM, Michalski J, Preston AJ, Yocom K, Friedman C (2001) The efficacy and safety of once-daily kytril (granisetron hydrochloride) tablets in the prophylaxis of nausea and emesis following fractionated upper abdominal radiotherapy. Cancer Invest 19:763-772

29. Lindeboom R, Vermeulen M, Holman R, De Haan RJ (2003) Activities of daily living instruments: optimizing scales for neurologic assessments. Neurology 60(5):738-742

30. Lindley CM, Hirsch JD, O'Neill CV, Transau MC, Gilbert CS, Osterhaus JT (1992) Quality of life consequences of chemotherapy-induced emesis. Qual Life Res 1(5):331-340

31. Maranzano E, Feyer PCh, Molassiotis A, Rossi R, Clark-Snow RA, Olver I, Warr D, Schiavone C, Roila F, Participants in the Perugia Consensus Conference 2004 (2005) Evidence-based recommendations for the use of antiemetics in radiotherapy. Radiother Oncol 76(3):227-233

32. Martin CG, Rubenstein EB, Elting LS, Kim YJ, Osoba D (2003) Measuring chemotherapy-induced nausea and emesis. Cancer 98 (3):645-655

33. Martin AR, Pearson JD, Cai B, Elmer M, Horgan K, Lindley C (2003) Assessing the impact of chemotherapy-induced nausea and vomiting on patients' daily lives: a modified version of the Functional Living Index-Emesis (FLIE) with 5-day recall. Support Care Cancer 11(8):522-527

34. Martin AR, Carides AD, Pearson JD, Horgan K, Elmer M, Schmidt C, Cai B, Chawla SP, Grunberg SM (2003) Functional relevance of antiemetic control: experience using the FLIE questionnaire in a randomised study of the NK-1 antagonist aprepitant. Eur J Cancer 39(10):1395-1401

35. The Antiemetic Subcommittee of the Multinational Association of Supportive Care in Cancer (MASCC) (1998) Prevention of chemotherapy- and radiotherapy-induced emesis: results of the Perugia Consensus Conference. Ann Oncol 9(8):811-819

36. Mystakidou K, Katsouda E, Linou A, Parpa E, Kouloulias V, Nikolaou V, Vlahos L (2006) Prophylactic tropisetron versus rescue tropisetron in fractionated radiotherapy to moderate or high emetogenic areas: a prospective randomized open label study in cancer patients. Med Oncol 23(2):251-262

37. Wong RK, Paul N, Ding K, Whitehead M, Brundage M, Fyles A, Wilke D, Nabid A, Fortin A, Wilson D, McKenzie M, Ackerman
I, Souhami L, Chabot P, Pater J, National Cancer Institute of Canada Clinical Trials Group (SC19) (2006) 5-hydroxytryptamine-3 receptor antagonist with or without short-course dexamethasone in the prophylaxis of radiation induced emesis: a placebo-controlled randomized trial of the National Cancer Institute of Canada Clinical Trials Group (SC19). J Clin Oncol 24(21):3458-3464

38. Onelöv E, Steineck G, Nyberg U, Hauksdóttir A, Kreicbergs U, Henningsohn L, Bergmark K, Valdimarsdóttir U (2007) Measuring anxiety and depression in the oncology setting using visualdigital scales. Acta Oncol 46(6):810-816

39. Osoba D, Zee B, Warr D, Latreille J, Kaizer L, Pater J (1997) Effect of postchemotherapy nausea and vomiting on health-related quality of life The Quality of Life and Symptom Control Committees of the National Cancer Institute of Canada Trials Group. Support Care Cancer 5(4):307-313

40. Priestman TJ, Roberts JT, Lucraft H, Collis CH, Adams M (1990) Results of a randomized, double-blind comparative study of ondansetron and metoclopramide in the prevention of nausea and vomiting following high-dose upper abdominal irradiation. Clin Oncol 2:71-75

41. Richardson MA, Sanders T, Palmer JL, Greisinger A, Singletary SE (2000) Complementary/alternative medicine use in a comprehensive cancer center and the implications for oncology. J Clin Oncol 18(13):2505-2514

42. Roila F, Ciccarese G, Palladino MA, De Angelis V (1998) Prevention of radiotherapy-induced emesis. Tumori 84(2):274-278

43. Roscoe JA, Morrow GR, Hickok JT, Stern RM (2000) Nausea and vomiting remain a significant clinical problem: trends over time in controlling chemotherapy-induced nausea and vomiting in 1413 patients treated in community clinical practices. J Pain Symptom Manage 20(2):113-121

44. Schnell FM (2003) Chemotherapy-induced nausea and vomiting: the importance of acute antiemetic control. Oncologist 8(2):187-198

45. Sloan JA, Frost MH, Berzon R, Dueck A, Guyatt G, Moinpour C, Sprangers M, Ferrans C, Cella D, Clinical Significance Consensus Meeting Group (2006) The clinical significance of quality of life assessments in oncology: a summary for clinicians. Support Care Cancer 14(10):988-998

46. Spitzer TR, Friedman CJ, Bushnell W, Frankel SR, Raschko J (2000) Double-blind, randomized, parallel-group study on the efficacy and safety of oral granisetron and oral ondansetron in the prophylaxis of nausea and vomiting in patients receiving hyperfractionated total body irradiation. Bone Marrow Transplant 26 (2):203-210

47. Sprangers M (2002) Quality-of-life assessment in oncology. Achievements and challenges. Acta Oncol 41(3):229-237

48. Steineck G, Bergmark K, Henningsohn L, al-Abany M, Dickman PW, Helgason A (2002) Symptom documentation in cancer survivors as a basis for therapy modifications. Acta Oncologica 41(3):244-252

49. Steineck G, Hunt H, Adolfsson J (2006) A hierarchical step-model for causation of bias-evaluating cancer treatment with epidemiological methods. Acta Oncol 45(4):421-429

50. Sun CC, Bodurka DC, Donato ML, Rubenstein EB, Borden CL, Basen-Engquist K, Munsell MF, Kavanagh JJ, Gershenson DM (2002) Patient preferences regarding side effects of chemotherapy for ovarian cancer: do they change over time? Gynaecol Oncol 87(1):118-128

51. Sykes AJ, Kiltie AE, Stewart AL (1997) Ondansetron versus a chlorpromazine and dexamethasone combination for the prevention of nausea and vomiting: a prospective, randomised study to assess efficacy, cost effectiveness and quality of life following single-fraction radiotherapy. Support Care Cancer 5(6):500-503

52. Tonini G, Vincenzi B, Santini D, La Cesa A, Finolezzi E, Onori N, D'Angelillo R, Baldi A, Trodella L (2003) Prevention of radiotherapy-induced emesis. J Exp Clin Cancer Res 22(1):17-22 